\title{
Health information systems in Jordan and Palestine: the need for health informatics training
}

Hussein Jabareen, ${ }^{1}$ Yousef Khader $^{2}$ and Adel Taweel ${ }^{3}$

${ }^{1}$ College of Nursing, Hebron University, Hebron, Palestine (Correspondence to: Hussein Jabareen: husseinj@hebron.edu). ${ }^{2}$ Department of Public Health, Jordan University of Science and Technology, Irbid, Jordan. ${ }^{3}$ Department of Computer Science, Birzeit University, Ramallah, Palestine.

\begin{abstract}
Background: Some Arab countries have health information systems (HIS) in place but they lack well trained IT staff. Poor management and lack of appreciation of the importance of HIS are major barriers to development and adoption of HIS in Arab hospitals.
\end{abstract}

Aims: This research is part of a survey carried out to determine health informatics (HI) use and to assess the training needs of health professionals in Jordan and Palestine.

Methods: A survey was conducted in 2017 among employees in all health professions at 14 hospitals in Jordan and Palestine to assess their use of the HI system and to assess the HI skills needed in both countries.

Results: The majority of respondents reported that their hospital departments were employing computer systems to run services. More than half had received training in computer skills but also half said they needed specialized training in HI. Between $58.0 \%$ and $73.6 \%$ agreed that their hospitals provided the necessary support to operate HI systems. The vast majority (86.0\%) of health professionals reported that they needed skills to monitor diagnosis and treatment, including access to clinical findings. Other skills needed included using shared hospital services (85.6\%), using medical records (84.7\%), managing electronic patient data (84.5\%), using patient medical records to conduct clinical research (83.4\%), and using tele-care services and technologies effectively (75.9\%).

Conclusions: Health professionals in Palestine and Jordan are in need of training in HI and therefore educational programmes in the area of $\mathrm{HI}$ are strongly recommended.

Keywords: health information systems, health informatics, health professionals, Jordan, Palestine

Citation: Jabareen H; Khader Y; Taweel A. Health information systems in Jordan and Palestine: the need for health informatics training. East Mediterr Health J. 2020;26(11):1323-1330. https://doi.org/10.26719/emhj.20.036

Received: 22/05/19; accepted: 16/12/19

Copyright (C) World Health Organization (WHO) 2020. Open Access. Some rights reserved. This work is available under the CC BY-NC-SA 3.0 IGO license (https://creativecommons.org/licenses/by-nc-sa/3.o/igo)

\section{Introduction}

Using computer and health informatics is critically important in improving the quality of the health care system, patient care and health outcomes (1). Health information systems (HIS) or health informatics (HI) is a multidisciplinary domain that utilizes health information technology (HIT) to enhance health care services via any combination of higher efficiency, higher quality and new opportunities. The HIS is information design and build applied to the field of health care, essentially "the management and utilization of patient health care information" (2). Electronic health systems are being used by health professionals to implement daily care management, avoid complications, prevent medical and medication errors, and carry out clinical research $(3,4)$. Electronic health systems make the management of patient records easier and safer while HI supports health professionals, consumers, patients and other stakeholders in their decision-making to achieve desired outcomes. This support is accomplished through the use of information structures, information processes and information technology $(5,6)$.

Most of the Arab countries are lagging behind in using an HIS due to lack of financial resources and staff competencies (7). There is a huge gap between the
Arab and Western countries in the information systems available (and used) (8-10). However, it seems that both groups of countries are facing similar challenges in the enforcement of HISs (11). For instance, in an international comparison of factors inhibiting physicians' use of HIS in the United States, Chile and Germany, Gewald et al. found that each country developed its own HIS but took a unique approach to fostering the implementation of IT in their health care settings and applied it differently at each management level (12). They reported that leadership and management structures had a significant role in the Western health care services in fostering the use of IT allied with the user, system, and process obstacles. Similarly, each Arab country had a unique culture and approach to health services, so HIS had to be specific and appropriate and in keeping with specific health policies (13). In many health care institutions, data are collected manually on paper rather than by digital data entry, but still the collected data are not complete, which results in a burden for patient monitoring as well as data analysis. In addition, regulations regarding the ethical use of clinical data are not adequate in many Arab countries (14). It is essential that health policy experts, researchers and other professionals create systems and policies that are comprehensive and improve health care services (15). 
Some Arab countries have an HIS in place but they lack well trained IT staff, data collectors, data entry personnel and data analysts (7). Poor management and bureaucracy as well as a lack of appreciation of the importance of HIS are major barriers to the development and adoption in Arab hospitals (16). Cost was an obstacle to HIS development in many Arab countries, but it was less of a concern in Saudi Arabia compared with others (16). The shortage, however, of competent IT staff was an obstacle in Syria and Saudi Arabia. Some efforts are under way to address these shortcomings, but more financial resources need to be allocated to further develop IT human resources and an HIS that fit local needs.

In many Arab countries, poor funding is the main obstacle to implementing the HIS, while in countries of the Gulf Cooperation Council, economic funds are available but the main barriers were the lack of qualified personnel, the lack of engagement of clinical staff in utilizing HIS, and ethical and privacy concerns $(17,18)$. According to Alsadan et al., Saudi Arabia and the United Arab Emirates were the most advanced Arab countries in utilizing an HIS (7), the authors recommended that cooperation and exchange of experiences between different Arab countries is needed to overcome some of the common barriers in implementing HIS.

Hayajneh and Zaghloul recommended that medical and health curricula should be revised to include and integrate HIS and that new programmes in HI should be established (16). Similar findings were reported by Shaban et al. in 2010 in their study on trauma registry in the United Arab Emirates, where the lack of funding and resources, the lack of qualified personnel in $\mathrm{HI}$ and the need for user friendly software for data entry were the main barriers (19). In developed countries such as the United States, despite its advancement in HI, barriers to using electronic health records as revealed by studies conducted over 10 years earlier were mainly costs and technical and communication difficulties (20). Academic institutions in the Arab world successfully provide national and international health institutions with qualified health care professionals, including medical doctors, pharmacists and nurses, while HI remains a newer field. With the recent realization and emphasis on the need for HI, some universities in the Arab countries have started providing a few courses, tracks or degrees in HI. In Egypt, Jordan and Palestine a few universities provide HI training and courses for undergraduate students in the health and IT fields. In Saudi Arabia and the United Arab Emirates, some universities offer advanced degrees in HI. The current situation in the Arab world requires further development of academic programmes that can meet the needs of health care providers $(15,21)$.

In Palestine and Jordan, HIS has recently been implemented in some areas but with various challenges and obstacles, and its application is still limited to electronic patient records (22). HiCure is an Erasmus + funded project. The project has a well-placed international consortium that combines strong academic and industrial expertise in both computing and health to develop innovative, integrated HI curricula. The HiCure project develops $\mathrm{HI}$ as integrated pathways within the undergraduate degrees of both the information technology and health-oriented programmes in Palestine and Jordan. The development of HI skills integrated within the existing degrees will ensure graduate students with competent skills founded on a solid grounding within their educational background. In addition to meeting their intended educational learning outcomes, HI skills will also become an essential part of students' profession employed as mechanisms that will improve the quality of health care by graduates qualified in both health and computing, and advance the health domain towards information-driven, efficient and effective evidence-based practice $(23,24)$.

Implementation of HIS is complex and relies on organizational, structural, technological and human factors to be complementary and successful (25). Assessing the impact of a complex HIS from the perspective of users is considered one of the most efficient evaluation methods in comparison with other methods (26). Although the use of HIS has pervaded health care settings in the Arab world and worldwide, methodologies to evaluate its impact in these settings have not developed with the same momentum (4). So, our study aimed to assess the use of HIS by health professionals and assess the needed HI skills in Palestine and Jordan.

\section{Methods}

A descriptive cross-sectional design was conducted among employees of all health professions at 14 governmental, nongovernmental, and private hospitals in Jordan and Palestine. A sample of health professionals was selected from those who were working in these hospitals during the period March-June 2017. Within each hospital, the study questionnaire was randomly administered to $20 \%$ of the total number of employees.

This study is part of a survey that was carried out to determine HI usage and to assess the training needs of health professionals in Jordan and Palestine. Two methods of sampling were adopted to satisfy the declared objectives of the study. The first method was a purposeful (convenience) sampling technique which was used to access targeted hospitals. Letters, questionnaire, and information sheets about the study were sent to the ministries of health responsible for governmental hospitals and to the administrations of nongovernmental hospitals asking their permission to allow the research team to distribute the questionnaire and collect data from health professions employees. All 14 hospitals we approached agreed to participate in this study. The second sampling procedure was within each hospital, where the research team targeted the available employees who were on duty during data collection shift. The data collection process was facilitated by permissions granted from the Jordanian and Palestinian ministries of health and the administrations of the nongovernmental hospitals. 
This facilitated entering these hospitals during different working shifts to reach as many diverse employees as possible and include opinions of all health professionals. Participants were recruited from 3 working shifts (day, evening, night) from each hospital during the data collection phase. Data collection started with the available health employees in the different departments in the day shift. After that, the research team revisited the hospitals during the evening and night shifts.

The questionnaire sought information about demographic characteristics of participants, use of computerized health systems, organizational support for $\mathrm{HI}$, training and usage of HI, and the needed HI skills. The perception of employees regarding the importance and adequacy of $\mathrm{HI}$ for health care practice at their institutions was explored by asking 10 questions using a 5-point Likert-type scale. The questionnaire was selfcompleted, filled out within the hospital setting during the break time in a place that was convenient to each participant. Completing the questionnaire took on average 10 minutes.

Ethical approval was obtained from the Institutional Review Board at Jordan University of Science and Technology.

Data were analysed using SPSS, version 20. Data were described using means, medians, and percentages as appropriate.

\section{Results}

\section{Participants}

A total of 579 health employees from 14 hospitals responded to the questionnaire, a response rate of $83 \%$. About 34\% of the respondents were from Jordan and 66\% from Palestine. The mean age of the respondents was 32 (range 20-65) years. About 18\% had a Diploma, $71 \%$ a Bachelor's degree and 7\% a post graduate degree (High Diploma, Masters, $\mathrm{PhD}$, or specialization in medicine). About $75 \%$ of the respondents were employed in governmental hospitals, $14 \%$ in nongovernmental hospitals, and

\begin{tabular}{lc}
\hline Table $\mathbf{1}$ Distribution of Jordanian and Palestinian health \\
professionals $(\boldsymbol{n}=\mathbf{5 7 9})$ according to department/unit, 2017 \\
\hline Department/unit & $\%$ \\
\hline Medical department & 25.7 \\
Allied health department & 19.2 \\
Surgical department & 16.2 \\
High dependency unit & 12.8 \\
Paediatrics department & 4.5 \\
Outpatient clinics & 4.3 \\
Administration & 3.8 \\
Emergency room & 3.3 \\
Maternity department & 3.1 \\
Operation room & 2.1 \\
Other & 5.0 \\
\hline
\end{tabular}

$11 \%$ in private hospitals. The survey covered all health units in hospitals. About $74 \%$ of respondents were working in the major medical, surgical, allied health and high dependency departments (Table 1). However, 5\% stated they were working in other departments not listed in the questionnaire.

\section{Years of experience}

The median years of experience in the profession was 5 (range 1-35) years. While the median experience in using computer systems was 4 (range 0-30) years. The median duration of using HIS was 2 (range 0-23) years. The majority of professionals in Palestinian and Jordanian hospitals started recently to use health computerized systems, and more than one-fifth did not have any experience with $\mathrm{HI}$ (Table 2).

\section{Computer use in institutions}

At the institutional level, more than $67 \%$ of respondents reported that their hospital departments were employing computer systems to run their services, especially in financial management $(77 \%)$, medical laboratory $(74 \%)$, pharmacy $(71 \%)$, electronic records $(67 \%)$, and top management $(66 \%)$ (Table 3).The use of computer systems was reported to a lesser extent for electronic prescriptions $(59 \%)$ and managing medical devices (50\%).

\section{Use of computer by physicians, allied health professionals, and nurses}

When the analysis was limited to physicians, allied health professionals and nurses, $84.9 \%$ in Palestine and $68.8 \%$ in Jordan reported that they used computers to carry out their duties (Table 4). Nurses and allied health professionals in Palestine were more likely to report the use of computers to accomplish their tasks. About 75.3\% of health professionals in Palestine and $62.2 \%$ in Jordan reported the use of electronic medical records. Nurses and allied health professionals in Palestine were more likely to report the use of electronic medical records than those in Jordan.

\section{Training on computer use for health professionals}

More than half of health professionals received training on computer skills (Table 4). Almost the same proportion reported that they needed specialized training in $\mathrm{HI}$ (Table 5). The majority of health professionals perceived that it is important to have HIS in their institution and about $52 \%$ of Jordanian and $60 \%$ of Palestinian health professionals reported that their institutions had adequate HIS (Table 5).

\section{Organizational support for health informatics}

Most employees were satisfied with the support provided by their organizations for the use of HI programmes (Table 6). For instance, about three-quarters (73.6\%) reported that their institutions provided a supportive environment for HI programmes; two-thirds $(66.9 \%)$ reported that their institutions had the necessary infrastructure 


\begin{tabular}{|c|c|c|c|c|c|c|}
\hline \multirow[t]{2}{*}{ Years of experience } & \multicolumn{2}{|c|}{ In health profession } & \multicolumn{2}{|c|}{ Using computer systems } & \multicolumn{2}{|c|}{$\begin{array}{c}\text { Using health information } \\
\text { systems }\end{array}$} \\
\hline & No. & $\%$ & No. & $\%$ & No. & $\%$ \\
\hline 0 & 0 & 0 & 67 & 12 & 120 & 22 \\
\hline $1-5$ & 279 & 50 & 266 & 48 & 376 & 68 \\
\hline $6-10$ & 123 & 22 & 108 & 19 & 48 & 8 \\
\hline $11-15$ & 63 & 12 & 86 & 16 & 7 & 1 \\
\hline $16-35$ & 89 & 16 & 27 & 5 & 3 & 1 \\
\hline Total & 554 & 100 & 554 & 100 & 554 & 100 \\
\hline
\end{tabular}

that enables clinicians while using $\mathrm{HI}$ and their institutions were committed to promoting and improving the implementation of HIT (68.3\%).

\section{The needed health informatics skills}

The majority of health professionals reported that they were in need of HI skills (Table 7); 86.0\% reported that they needed skills to monitor patients' diagnosis and treatment, including access to clinical findings. Other skills needed included using shared hospital services (85.6\%), using medical records (84.7\%) and managing electronic patient data (84.5).

\section{Discussion}

The findings of this survey have several significant theoretical and practical implications for academia, the health care sector and government. Having experience in computer systems makes it easy to learn HI systems. In particular, our results show that the use of computer systems is not limited to a specific department. The majority of the participants were using these systems in the medical laboratory and the pharmacy to run their daily transactions and operations. Electronic records and prescriptions were also used by almost two-thirds of the participants. Although one-third were using telemedicine, they demonstrated a strong willingness to expand the use to facilitate their daily tasks.

In comparing the 2 countries, we found that nurses and allied health professionals in Palestine were more likely to report the use of the computer to accomplish their tasks. Additionally, nurses and allied health professionals in Palestine were more likely to report the use of electronic medical records than those in Jordan. Nevertheless, most Arab countries do not use HIT very often because of
Table 3 Use of computer systems according to department/ unit as reported by Jordanian and Palestinian health professionals $(n=579), 2017$

\begin{tabular}{lc} 
Professional department/unit & $\begin{array}{c}\text { Computer use } \\
\%\end{array}$ \\
\hline Financial management & 77 \\
Medical laboratory & 74 \\
Pharmacy & 71 \\
Electronic records & 67 \\
Top management & 66 \\
Electronic prescription & 59 \\
Managing medical devices & 50 \\
Logistics & 44 \\
Telemedicine in education & 32 \\
\hline
\end{tabular}

financial obstacles (7). In Jordan for example, the field of HIT started only recently, thus not many allied health professionals use it. However, it has been suggested that new health information technologies in the 21st century can transform the Arab world as societies need strong and efficient health policies to improve patient care (9). One possible reason for not widely adopting HIT in Jordan is the negative perception of its importance (16). Moreover, research in the region has shown that poor funding, lack of qualified personnel or their engagement in utilizing HIT are the main obstacle to implementing it (17).

There are some limitations to this study. It was carried out as part of a large survey to determine the extent of usage of HIS, to assess the training needs, and to explore the attitudes of health professionals in Jordan and Palestine towards HI. So, we neither tested any hypothesis nor examined associations between variables. The

\begin{tabular}{lcccc}
\hline $\begin{array}{l}\text { Table } 4 \text { Computer use and training by Jordanian and Palestinian health professionals } \\
\text { Profession }\end{array}$ & \multicolumn{2}{c}{ Computer use } & 579), 2017 & \multicolumn{2}{c}{ Training in computer skills } \\
& Jordan & Palestine & Jordan & Palestine \\
Physician & 79.5 & 80.7 & 67.5 & 47.4 \\
Nurse & 56.6 & 84.7 & 50.0 & 63.7 \\
Allied health professional & 70.0 & 88.8 & 45.2 & 56.3 \\
Overall & 68.8 & 84.9 & 56.8 & 59.4 \\
\hline
\end{tabular}


Table 5 Distribution of Jordanian and Palestinian health professionals $(n=579)$ perceptions of the health informatics situation in their institutions, 2017

\begin{tabular}{lcccccc} 
Profession & \multicolumn{2}{c}{$\begin{array}{c}\text { There is a need for specialized } \\
\text { training }\end{array}$} & \multicolumn{2}{c}{$\begin{array}{c}\text { Having a health information } \\
\text { system is important }\end{array}$} & \multicolumn{2}{c}{$\begin{array}{c}\text { Our health information system } \\
\text { is adequate }\end{array}$} \\
& Jordan & Palestine & Jordan & Palestine & Jordan & Palestine \\
Physicians & 49.4 & 50.9 & 81.7 & 75.4 & 59.8 & 52.6 \\
Nurses & 71.6 & 64.2 & 86.5 & 88.4 & 46.7 & 60.0 \\
Allied health professionals & 61.3 & 48.8 & 87.1 & 81.3 & 45.2 & 66.3 \\
Overall & 60.1 & 58.5 & 84.5 & 84.7 & 52.1 & 60.2 \\
\hline
\end{tabular}

sample size included $20 \%$ of health employees working in the targeted 14 hospitals but these could not be described as representative of all health employees in Jordan and Palestine. The survey was carried out in a stressful period after the introduction of HIS in many of these hospitals, and thus participants might not have been typical of all those in the original populations. Comparisons and similarities with other studies noted must therefore be treated with caution. Many studies, especially in the Arab world, have reported that workloads were increased after the introduction of HIS, and clinicians mainly complained about the increased paperwork and IT workload $(8,16,17)$. This raises the issue of the nonrespondents as they may perhaps have been the busiest professionals, those who could not find the time to fill out the questionnaire.

In order to make it comprehensive, the questionnaire covered a wide range of topics concerning the training needs and impact of HI usage at individual, institutional and national levels: the cost of this broad scope was the inability to focus on specific clinical or professional areas such as electronic prescribing and electronic triaging. Furthermore, the questionnaire contained many questions about previous experience with using computers and HIS and training of health professionals and this could have produced some recall bias. Furthermore, we did not investigate the duration of using computers by health professionals nor the onset or frequency of using electronic medical records. This is of paramount importance because sustainability is a critical factor in achieving improvements in patient health outcomes (27).
Another limitation of the analysis of this survey was the small numbers within the subgroups. About $74 \%$ of our respondents were working in 4 major medical, surgical, allied health and high dependency departments; only $21 \%$ were working in the remaining 6 departments, and $5 \%$ were working in various other departments. Nonetheless, the survey does throw up some potentially important issues concerning these subgroups.

Our results showed that more than half the health care professionals had some training in computers skills, however, large proportions among different professions in both cohorts reported needing more specialized training in HI, suggesting a perceived lack of confidence in their current knowledge. Similarly, in an Australian study, almost half the nurses indicated a need for more computer training to better meet their job requirements (28). In the same study, nurses, as the largest users of computer technology, considered that employers often did not encourage information and computer technology training. Consistent with this, Trivedi and Joshi reported that more than three-quarters of health care professionals in a rural medical college in India had no formal computer training (29).

Similar to the findings of a study in hospitals in Tehran (30), we found considerable variation in computer training experiences across the 3 groups of health professions in both settings. Physicians received more training than other health care professionals in the Jordan cohort, while nurses received more training in the Palestine cohort. Nurses in both countries perceived a higher need for more specialized training in $\mathrm{HI}$ and

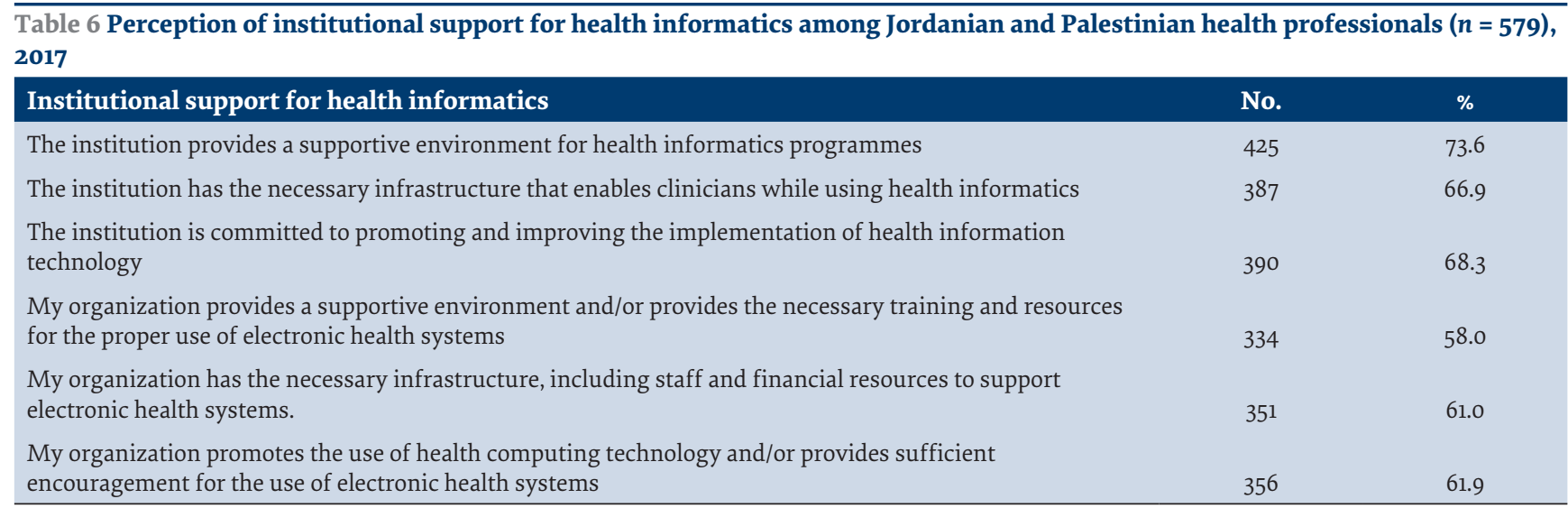




\begin{tabular}{|c|c|}
\hline Skill & $\%$ \\
\hline Monitoring patient diagnosis and treatment & 86.0 \\
\hline Using shared hospital services & 85.6 \\
\hline Using patient medical records & 84.7 \\
\hline Managing electronic patient data & 84.5 \\
\hline Using patient medical records for clinical research & 83.4 \\
\hline Telemedicine and tele-care services & 75.9 \\
\hline Using coding standards & 73.8 \\
\hline
\end{tabular}

computer skills than other health care professionals. Other researchers have reported similar interest among nurses towards enhancing their careers (13).
Finally, and although the majority of health care professionals in both setting believed that it was important to have HI system in their institutions, obstacles to implementing HIT still exist. To overcome the challenges related to the use of HIT by health professionals in Jordan and Palestine, medical and health curricula need to be revised to include and integrate HIT, and new programmes in $\mathrm{HI}$ need to be developed (16). Indeed, some universities in Jordan and Palestine have recently started to provide $\mathrm{HI}$ training and courses for undergraduate students in the health and IT fields.

In conclusion, health professionals in Palestine and Jordan are in need for training in $\mathrm{HI}$ and therefore educational programmes in the area of $\mathrm{HI}$ are strongly recommended.

\section{Acknowledgement}

This paper reflects the views only of the authors; the European Commission cannot be held responsible for any use which may be made of the information contained therein. The authors would like to thank the HiCure members who contributed to this study.

Funding: This study, part of the HiCure project, has been funded with support from the European Commission.

Competing interests: None declared.

\section{Systèmes d'information sanitaire en Jordanie et en Palestine : nécessité d'une formation en informatique sanitaire}

\section{Résumé}

Contexte : Certains pays arabes disposent de systèmes d'information sanitaire, mais ils manquent de personnel informatique bien formé. Une mauvaise gestion et un manque d'appréciation de l'importance des systèmes d'information sanitaire constituent des obstacles majeurs au développement et à l'adoption de ces systèmes dans les hôpitaux du monde arabe.

Objectifs : La présente recherche fait partie d'une enquête menée pour déterminer l'utilisation de l'informatique sanitaire et pour évaluer les besoins de formation des professionnels de santé en Jordanie et en Palestine.

Méthodes : En 2017, une enquête a été menée auprès des employés de toutes les professions de santé de 14 hôpitaux en Jordanie et en Palestine afin d'évaluer leur utilisation du système d'information sanitaire et de déterminer les compétences en informatique sanitaire nécessaires dans les deux pays.

Résultats : La majorité des répondants ont indiqué que leurs services hospitaliers utilisaient des systèmes informatiques pour gérer leurs services. Plus de la moitié a reçu une formation en informatique, mais la moitié a également déclaré avoir besoin d'une formation spécialisée en informatique sanitaire. Entre $58,0 \%$ et $73,6 \%$ ont convenu que leurs hôpitaux fournissaient le soutien nécessaire au fonctionnement des systèmes d'information sanitaire. La grande majorité $(86,0 \%)$ des professionnels de santé ont déclaré avoir besoin de compétences pour surveiller le diagnostic et le traitement, y compris l'accès aux résultats cliniques. Les autres compétences nécessaires comprenaient le recours aux services hospitaliers partagés (85,6\%), l'utilisation des dossiers médicaux $(84,7 \%)$, la gestion électronique des données des patients $(84,5 \%)$, l'utilisation des dossiers médicaux des patients pour mener des recherches cliniques $(83,4 \%)$ et l'utilisation efficace des services et des technologies de télésoins (75,9\%).

Conclusions : Les professionnels de santé en Palestine et en Jordanie ont besoin d'une formation en informatique sanitaire. Par conséquent, des programmes d'éducation dans ce domaine sont fortement recommandés. 
نُطم المعلومات الصحية في الأردن وفلسطين: الحاجة إلى التدريب في مجال المعلوماتية الصحية

حسين جبارين، يوسف خضر، عادل الطويل

الخلاصة

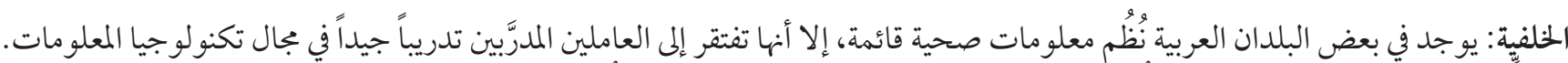

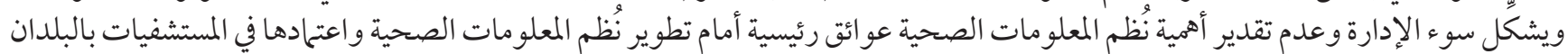
العربية.

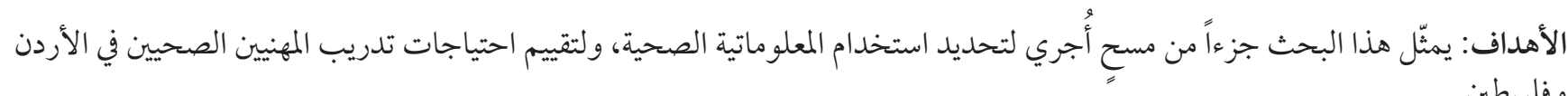
وفلسطين. طرق البحث: أُجري مسح في عام 170 أج 20 للعاملين في جميع المهن الصحية في 14 مستشفى في الأردن وفلسطين لتقييم استخدامهم لنظم المعلومات

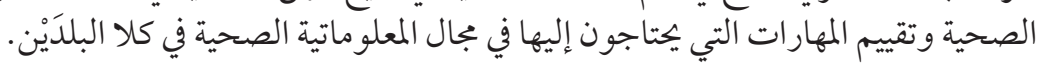

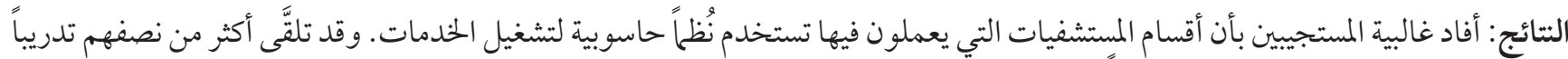

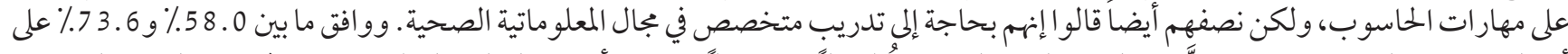

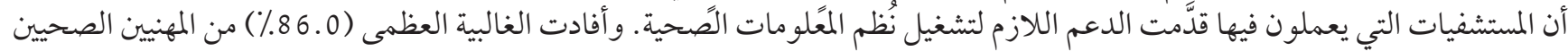

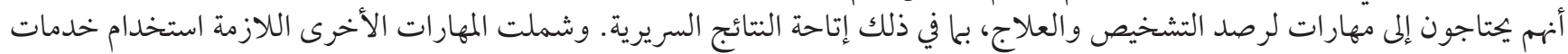

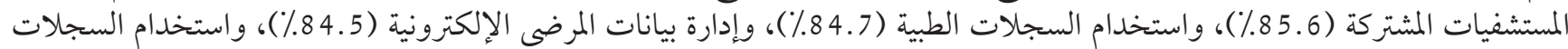

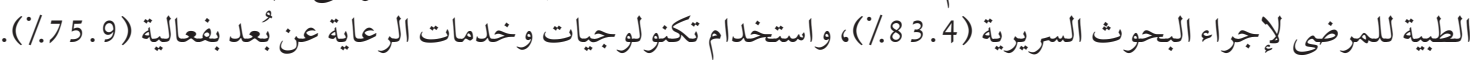

الاستنتاجات: يجتاج المهنيون الصحيون في فلسطين والأردن إلى التدريب في ججال المعلو ماتية الصحية، ولذلك يوصَى بشدة بتوفير برامج تعليمية في هذا المجال.

\section{References}

1. Benbrahim H, Hachimi H, Amine A. Moroccan Electronic Health Record System. In: Proceedings of the International Conference on Industrial Engineering and Operations Management Paris, France, July 26-27, 2018.

2. Nadri H, Rahimi B, Timpka T, Sedghi S. The top 100 articles in the medical informatics: a bibliometric analysis. J Med Syst. 2017 Aug 19;41(10):150. doi:10.1007/s10916-017-0794-4

3. Almuayqil S, Atkins AS, Sharp B. Ranking of E-health barriers faced by Saudi Arabian citizens, healthcare professionals and IT specialists in Saudi Arabia. Health. 2016;08(10):1004-13. doi:10.4236/health.2016.810104

4. Cresswell K, Sheikh A.. Organizational issues in the implementation and adoption of health information technology innovations: an interpretative review. Int J Med Inform. 2013 May;82(5):e73-86. doi:10.1016/j.ijmedinf.2012.10.007

5. Badran MF. Electronic health records prospects in Egypt: a demand-side perspective. Paper presented at the 28th European Regional ITS Conference, Passau, Germany, 30 July-2 August 2017.

6. Bouhaddou O, Bennani Othmani M, Diouny S. Medical informatics in Morocco. Yearb Med Inform. 2013;8:190-6. PMID:2397457

7. Alsadan M, El Metwally A, Ali A, Jamal A, Khalifa M, Househ M. Health information technology (HIT) in Arab countries: a systematic review study on HIT progress. J Health Inform Dev Countries. 2015;9(2):32-49.

8. Alrawabdeh W, Salloum A, Mingers J. Key factors influencing the diffusion of information and communication technology (ICT) in the Arab world. A comparative study. Brit J Econom, Finance Management Sci. 2012;5(2):45-59.

9. Almulhim DA, Househ MS. A perspective on the influence of health policy on health technology use within the Arab world. J Health Inform Dev Countries. 2012;6(1):375-84.

10. Berg M. Implementing information systems in health care organizations: myths and challenges. Int J Med Inform. 2001;64:14356. doi:10.1016/s1386-5056(01)00200-3

11. Waterson P, Hoonakker PL, Carayon P. Special issue on human factors and the implementation of health information technology (HIT): comparing approaches across nations. Int J Med Inform. 2013;82: 277-80. doi:10.1016/j.ijmedinf.2013.01.001

12. Gewald H, Núñez A, Gewald C, Vriesman LJ. An international comparison of factors inhibiting Physicians' use of hospital information systems. In: Proceedings CONF-IRM. 2017 (http://aisel.aisnet.org/confirm2017/1, accessed 2 April 2010).

13. Eldin AS, Saad D, Samie GA. Evaluation of electronic health records adoption in Egypt. Int J Engineer Res Applications. 2013;3(1):1131-4.

14. Abd Ghani MK, Neamah AF. Electronic health records challenges and barriers in Iraq. Comp Engineer Intelligent Systems. 2017;7(6):1-7. 
15. Moghaddasi H, Mohammadpour A, Bouraghi H,. Azizi A, Mazaherilaghab H. Hospital information systems: the status and approaches in selected countries of the MiddleEast. Electron Physician. 2018;10(5):6829-35. doi:10.19082/6829

16. Hayajneh YA, Zaghloul AA. Barriers to the adoption of health information technology in arab countries' hospitals: practitioners' perspective. In: 24th International Conference of the European Federation for Medical Informatics: Quality of Life through Quality of Information, 2012.28-29 August 2012.

17. Alkraiji AI, El-Hassan O, Amin FA. Health informatics opportunities and challenges: preliminary study in the Cooperation Council for the Arab States of the Gulf. J Health Inform Dev Countries. 2014;8(1):36-45

18. Sabur DS, Neamah AF. Electronic health in Iraq. Int J Adv Res. 2016;4(8):295-305.

19. Shaban S, Eid HO, Barka E, Abu-Zidan FM. Towards a national trauma registry for the United Arab Emirates. BioMed Central Res Notes. 2010;3(1):187. doi:10.1186/1756-0500-3-187

20. Ajami S, Arab-Chadegani R. Barriers to implement electronic health records (EHRs). Mater Sociomed. 2013;25(3): 213-5. doi:10.5455/msm.2013.25.213-215

21. Wageih MA, Marcano-Cedeño A, Gómez EJ, Mantas J. Toward more successful biomedical informatics education programs and ecosystems in the Arab world. Studies in health technology and informatics, 2015;213:111-4. PMID:26152967

22. Palestinian health capacity project. Palestinian ministry of health saves money, improves quality of care through its health information system. Washington DC: USAID and Intrahealth International; 2018 ( https://www.intrahealth.org/sites/ihweb/files/ attachment-files/phcphistubasimplementation.pdf, accessed 27 March 2020).

23. Khader Y, Jabareen H, Alzyoud S, Awad S, Rumeileh NA, Manasrah N, et al. Perception and acceptance of health informatics learning among health-related students in Jordan and Palestine. In: IEEE/ACS 15th International Conference on Computer Systems and Applications (AICCSA), 1 October 2018:16. (http://sites.birzeit.edu/hicure/, accessed 20 August 2019).

24. Al-Shorbaji, N. Househ, M. Taweel, A. Alanizi, A. Mohammed, B.O. Abaza, H. et al. (2018). Middle East and North African Health Informatics Association (MENAHIA): Building Sustainable Collaboration. Yearbook Med Informatics. 27(1):286-91.

25. Sligo J, Gauld R, Roberts V, Villa L. A literature review for large-scale health information system project planning, implementation and evaluation. Int J Med Inform. 2017;97:86-97. doi:10.1016/j.ijmedinf.2016.09.007

26. Aggelidis VP, Chatzoglou PD. Methods for evaluating hospital information systems: a literature review. EuroMed J Bus. 2008;3:99-118.

27. Luna D, Almerares A, Mayan JC, González Bernaldo de Quirós F, Otero C. Health informatics in developing countries: going beyond pilot practices to sustainable implementations: a review of the current challenges. Healthc Inform Res. 2014 Jan;20(1):3-10. doi:10.4258/hir.2014.20.1.3

28. Eley R, Fallon T, Soar J, Buikstra E, Hegney D. The status of training and education in information and computer technology of Australia's nurses : a national survey. J Clin Nurs. 2008 Oct;17(20):2758-67. doi:10.1111/j.1365-2702.2008.02285.x

29. Trivedi MJ, Joshi A. Computer and internet use by health care professionals in a rural medical college in India. Libr Philos Pract. 2008.

30. Sadoughi F, Hemma, M, Valinejadi A, Mohammadi A, Majdabadi HA. Assessment of health information technology knowledge, attitude, and practice among healthcare activists in Tehran hospitals. Int J Computer Sci Network Security. 2017;17(1):155-8. 